\title{
Development of Excellent Leadership Indicators of Administrators in Private Schools in Northeastern Thailand
}

\author{
Weerawat Sintupun ${ }^{1}$, Wichit Khammantakhun ${ }^{1} \&$ Thanyaporn Nualsing ${ }^{1}$ \\ ${ }^{1}$ Department of Educational Administration, Faculty of Education, Roi Et Rajabhat University, Roi Et, Thailand \\ Correspondence: Weerawat Sintupun, Department of Educational Administration, Faculty of Education, Roi Et \\ Rajabhat University, Roi Et, 45120, Thailand.
}

$\begin{array}{lcc}\text { Received: July 8, } 2021 & \text { Accepted: August 19, } 2021 & \text { Online Published: November 24, } 2021 \\ \text { doi:10.5539/ies.v14n12p60 } & \text { URL: https://doi.org/10.5539/ies.v14n12p60 }\end{array}$

\begin{abstract}
The purposes of this research were 1) to study existing excellent leadership indicators of private school administrators and 2) to test the consistency between the developed excellent leadership model and the empirical data. The sample group was consisted of 532 administrators and teachers in private schools in northeastern Thailand certified by the Office of Nation Education Standards and Quality Assessment (Public Organization), Thailand. They were obtained through purposive sampling. The research instruments for data collection included 1) a semi-structured interview form and 2) a 5-point rating scale questionnaire with a content validity between $0.60-1.00$ and a reliability of 0.992 . The data was analyzed with a statistical package and content analysis. The results of the research were as follows: 1 . The developed model of excellent leadership indicators of the private school administrators contained 5 core elements and 82 indicators including 1) transformational leadership with 4 sub-elements and 12 indicators, 2) strategic management leadership with 4 sub-elements and 15 indicators, 3) academic leadership with 4 sub-elements and 14 indicators, 4) corporate communication with 5 sub-elements and 21 indicators, and 5) technological skills with 6 sub-elements and 20 indicators. 2. The developed model of the excellent leadership indicators of the private school administrators was in consistence with the empirical data $\left(\right.$ Chi-square $=357.51, \mathrm{df}=149, \mathrm{p}=0.00000, x^{2} / \mathrm{df}=2.39, \mathrm{GFI}=0.94, \mathrm{AGFI}=0.90, \mathrm{RMSEA}=.0 .051, \mathrm{RMR}=$ $0.013)$.
\end{abstract}

Keywords: excellent leadership, indicators, indicator development, school administrators

\section{Introduction}

\subsection{Importance of Excellent Leadership in Educational Administration}

Administrators of educational institutions are regarded as the heart of education management. They need to possess certain leadership which is a key factor in educational administration. One of the most important leadership is excellent leadership. According to the existing concepts of excellent leadership, it is an important factor to drive educational institutions towards success. Based on the concepts of excellent leadership, a great number of scholars both in Thailand and abroad agree that success or failure in educational administration is largely dependent on administrators. Those administrators take a role as strategic leaders. In accordance with Kiral (2020), education policy makers in the 21st century are executives with excellent leadership. Excellent leadership behaviors help teachers become good teachers and enable successful classroom instruction. An excellent leader leads to positive change. It is a practice guideline for school administrators. From empirical or theoretical concepts, excellent leadership of school administrators is considered a continuous practice that benefits teachers and students, resulting in good efficiency in education. Williams and Denney (2016) add that there are seven aspects of excellent leadership in the 21st century; 1) vision, 2) communication, 3) skills, 4) personality, 5) executive ability, 6) courage, and 7) service mind.

\subsection{Components of Excellent Leadership}

A leader who is active in implementing strategies is able to motivate and influence others to pursue desired new strategies. Bass and Avolio (1994) summarized that transformational leadership is the process by which leaders influence coworkers and followers. This is done through four specific behavioral components known as "4I's (Four I's)"; 1) ideological influence, 2) inspiration, 3) intellectual stimulation, and 4) individual consideration. Sararatana (2004) gives a viewpoint on transformational leadership theory based on his study that 
transformational leadership motivates a person to perform tasks to exceed normal expectations. It is a broader mission-oriented practice with self-centered interest and an aim of achieving high demands such as job success rather than low demands like safety or security. Transformational leadership gives them confidence to use their abilities to accomplish tasks that are beyond normal expectations. This type of leadership does not replace managerial leadership, but it enhances or creates add-on effects.

From management leadership, it can be said that transformational leaders to be successful require some fundamental managerial leadership skills and that administrators have to be academic leaders. Sripraseart (2017) studied the academic leadership of the school administrators of opportunity expansion schools under the jurisdiction of Educational Bureau, Pattaya City, Thailand and found five elements of academic leadership; 1) mission establishment, 2) curriculum and instruction administration, 3) instructional supervision, 4) student progress monitoring, and 5) teaching and learning atmosphere enhancement. Excellent leadership that administrators of private educational institutions have to hold and practice is corporate communication (Saengkhammee, 2018). Corporate communication is generally consisted of six characteristics; 1) reliability of the sender and the source of information, 2) suitability of the situation, 3) continuation, 4) communication channels, 5) capacity of the receiver, and 6) clarity of information. Further excellent leadership that educational administrators have to employ is technological skills (Teecharoen \& Xupravati, 2019). Technological leadership contains six components; 1) technological vision, 2) technological competency, 3) support of the use of technology in administration, 4) support of the use of technology in teaching and learning, 5) use of technology in measurement and evaluation, and 6) ethics of technology use. It is important to drive the operation of an organization to success. Effective operation of an organization is partially a result of the leader's abilities to lead subordinates to success or to failure.

\subsection{Roles of Private Schools in Thailand}

In Thailand, private schools have always played an important role in providing educational services to lighten the load of the government, especially in sectors where the government is unable or insufficient to provide due to resource limitations. For this fact, to carry out the private education management with efficiency and quality in line with the national development guidelines, Office of the Private Education Commission was established on October 1, 1972 under the Ministry of Education to act as a supervisor and supporter for the private sector to provide quality education. Office of the Private Education Commission of Thailand is the only government agency responsible for the provision of education of under the undergraduate level in the private sector (Office of the Private Education Commission, 1997). The Constitution of the Kingdom of Thailand, B.E. 2550 (2007) stipulates that the State support the private sector in the provision of education, training to create both knowledge and morals, and taking into account the participation of the private sector (Office of the Permanent Secretary, Ministry of Education, 2000). National Education Act, B.E. 2542 (1999) and Amendments (Second National Education Act), B.E. 2545 (2002) states in Section 43, "The administration and management of education by the private sector shall enjoy independence with the State being responsible for overseeing, monitoring, and assessing educational quality and standards. Private educational institutions shall follow the same rules for assessment of educational quality and standards as those for state educational institutions."

\subsection{Private School Administration in Thailand}

For the administration under the modern education in the 21 st century, a huge number of private schools cannot adjust the traditional school administration. Those schools still follow their traditional patterns of administration and experience problems, obstacles from the rapidly changing environment or various difficult situations. On July 21st, Mr. Chalam Attatham, Secretary-General, Office of the Private Education Commission (OPEC), revealed that Office of the Private Education Commission made a comparison of the numbers of the private schools in the academic years 2018 and 2019. It was found that in the formal education system there were 4,003 general education schools in the academic year 2018 and 3,937 schools in the academic year 2019 (closed: 66 schools). There were 206 international schools in the academic year 2018 and 207 in the academic year 2019 (newly open: 1 school). Private schools in the non-formal education system include seminaries, arts and sports schools, vocational schools, tutorial schools, life skills school, pondok schools, and tadika schools. There were 10,538 schools in the academic year 2018 and 10,523 schools in the academic year 2019 (closed: 15 schools). In total, there were 14,747 schools in all types of schools under Office of the Private Education Commission in the academic year 2018 and 14,667 schools and in the academic year 2019 (closed: 80 schools). More private schools are expected to close down as a result of the economic and administration crises (Matichon, 2019).

From the reasons mentioned above, it was interesting to study theories and research by both national and international scholars to be adapted for the sustainability of private schools. Knowledge gained from those 
theories and studies can provide private school administrators with guidelines and ideas of excellent leadership. They can apply excellent leadership to solving problems in the administration for the sustainability of private schools. Therefore, this research on excellent leadership of private school administrators was conducted to enhance excellence in the administration of private schools. The importance of this research was that administrators and stakeholders of private schools made use of the research results as guidelines for more efficient and effective educational management and administration of private schools.

\section{Method}

\subsection{Conceptual Framework}

A study of concepts on excellent leadership and its characteristics proposed by national and international scholars was conducted. Based on Williams and Denney (2016), Benoit (2003), Cavallo (2001), McKibben, Webber, and Wahesh (2017), Singmatr, Meemana, and Kaewin (2017), Piungam, Suwannatrai, Pothiwat, and Palajit (2015), Srichan (2016), Purisarn (2017), Paopan (2016), Tokeaw (2016), Meng (2009), and general excellent leadership of private school administrators includes 1) transformational leadership, 2) strategic management leadership, 3) academic leadership, 4) corporate communication, 5) teamwork, and 6) technological skills. A hypothesized model of the excellent leadership and its six characteristics is presented in Figure 1.

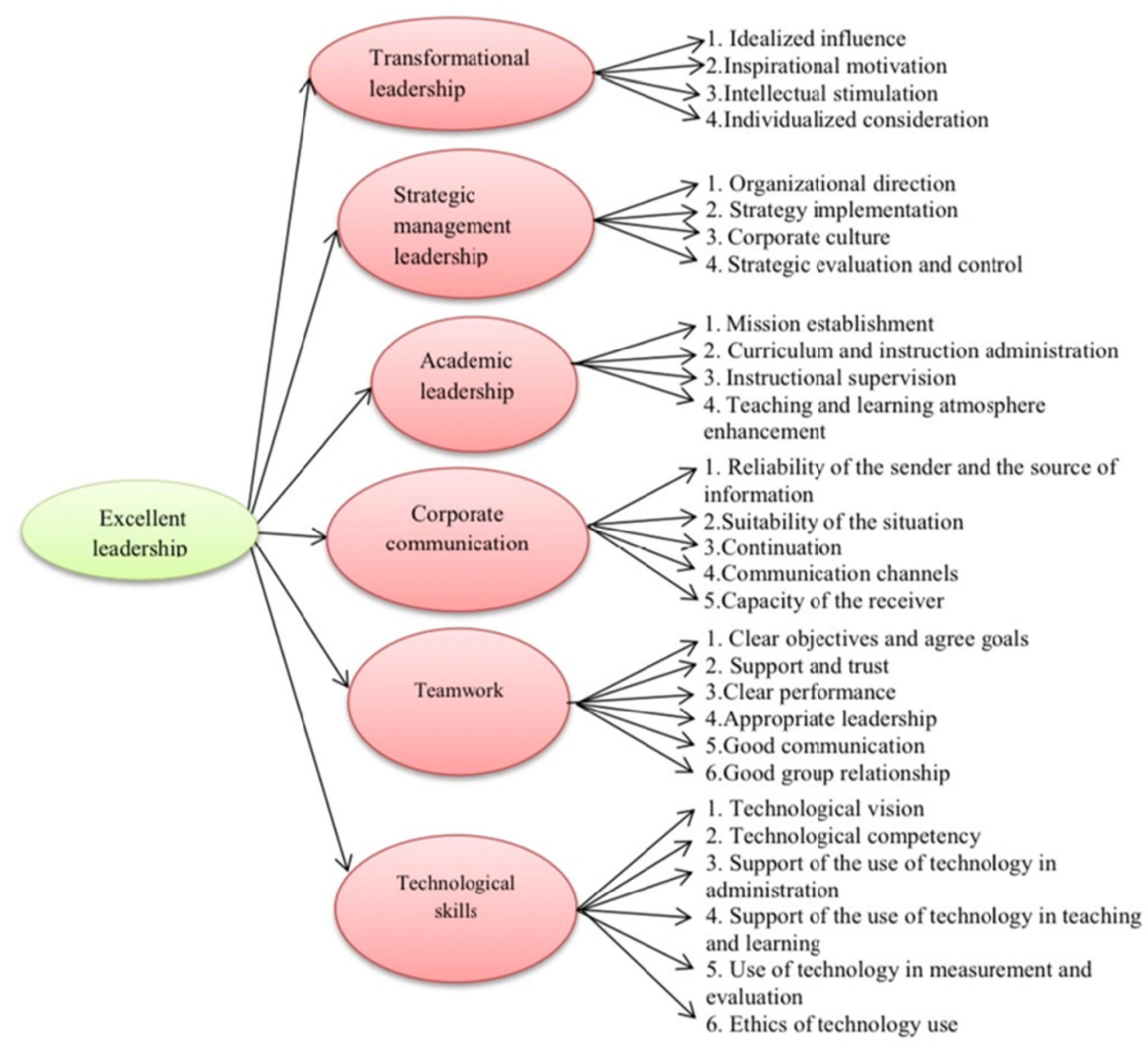

Figure 1. A hypothesized model of the excellent leadership of private school administrators

\subsection{Purposes of the Research}

1) To study prior excellent leadership indicators of private school administrators.

2) To test the consistency between the developed excellent leadership model and the empirical data.

\subsection{Hypothesis of the Research}

The excellent leadership indicators of the private school administrators in the developed model were in consistence 
with the empirical data.

\subsection{Research Methodology}

\subsubsection{Population and Samples}

Population and samples:

The population of this research was the administrators of the schools which had passed the third external assessment and certification of the basic education institutions by the Office for National Education Standards and Quality Assessment (Public organization). There were totally 1,710 schools across the country rated higher than the "good" level in the external assessment (From Office of the Private Education Commission, the academic year 2016).

The sample group was consisted of 532 educational personals (266 administrators and 266 teachers) of 266 private schools in the Northeast of Thailand obtained through purposive sampling. All these schools had passed the third external assessment and certification mentioned above.

Experts:

Seven experts in school administration participated in the research. They were obtained through purposive sampling. The qualifications for selection included knowledge and experience in educational administration, a Ph.D., and some academic works on leadership.

\subsubsection{Research Instruments}

The research instruments included a semi-structured interview form and a questionnaire with 2 parts.

Part 1: Status of Respondent: The checklist of this part collected the gender, age, educational background, work position, and work experience.

Part 2: Six core elements: This part was divided into six sets of questions according to the six core elements as follows; 1) transformational leadership with 12 questions, 2) strategic management leadership with 15 questions, 3) academic leadership with 14 questions, 4) corporate communication with 24 questions, 5) teamwork with 15 questions, and 6) technological skills with 20 questions.

After the questionnaire was drafted, it was tried out among non-samples selected from different districts. The questionnaire copies returned from the non-samples were analyzed for reliabilities with Cronbach's alpha coefficient. The reliabilities of the six sets of questions as the six core elements were as follows; 1) 0.996 (transformational leadership), 2) 0.958 (strategic management leadership), 3) 0.949 (academic leadership), 4) 0.971 (corporate communication), 5) 0.966 (teamwork), and 6) 0.958 (technological skills). The reliability of the whole questionnaire was 0.992 . The questionnaire was then refined according to these try-out results before collecting the empirical data from the samples.

\subsubsection{Data Collection}

Copies of the questionnaire and the cover letter were posted to the samples-532 educational personals (266 administrators and 266 teachers) of 266 private schools in the Northeast of Thailand. The questionnaire was also prepared in the form of Google form as an alternative for the samples. The data collection took place between October and November 2020.

\subsubsection{Data Analysis}

The data was analyzed with basic descriptive statistics such as mean, standard deviation, kurtosis, and skewness to explain the data distribution. The correlation coefficient was analyzed for the matrix suitability and correlation between variables. KMO and Bartlett's test of sphericity were also analyzed.

The first order confirmatory factor was analyzed to examine the developed model whereas the second order confirmatory factor was analyzed to verify the construct validity. The analysis was conducted through statistical software.

The consistency between the excellent leadership model developed in this research and the empirical data collected from the samples was tested with the following statistics; Chi-square (p-value $>0.05$ ), Goodness of Fit Index (GFI), Adjusted Goodness of Fit Index (AGFI) (p-value $>0.90$ ), Root Mean Square Residual Index (RMR), Root Mean Square Error of Approximation (RMSEA) (p-value $\leq 0.80$ ). The results of the test were used to select indicators with construct validity of Factor Loading equal to or greater than 0.30 and the appropriateness mean equal to or greater than 3.50 . 


\section{Results of the Research}

The developed model of the excellent leadership indicators of the private school administrators contained 5 core elements with 82 indicators as follows; 1) transformational leadership with 4 sub-elements and 12 indicators, 2) strategic management leadership with 4 sub-elements and 15 indicators, 3) academic leadership with 4 sub-elements and 14 indicators, 4) corporate communication with 5 sub-elements and 21 indicators, and 5) technological skills with 6 sub-elements and 20 indicators.

The developed model of the excellent leadership indicators of the private school administrators was in consistence with the empirical data (Chi-square $=357.51, \mathrm{df}=149, \mathrm{p}=0.00000, x^{2} / \mathrm{df}=2.39, \mathrm{GFI}=0.94, \mathrm{AGFI}=0.90$, RMSEA $=.0 .051$, RMR $=0.013$ ) as presented in Figure 2 .

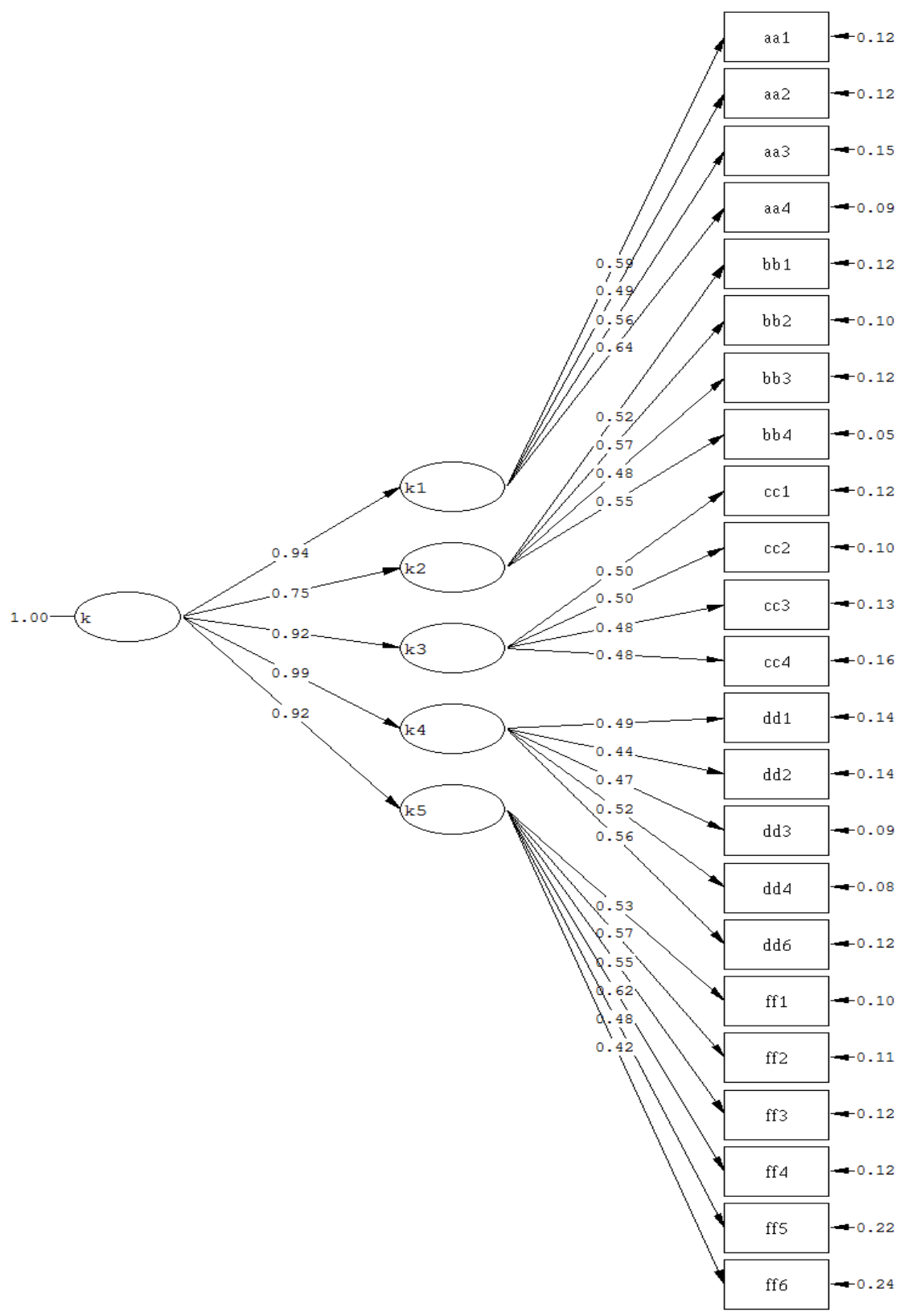

Figure 2. The developed model of the excellent leadership indicators of the private school administrators 
Table 1. Results of the second order confirmatory factor analysis of the excellent leadership indicators of the private school administrators

\begin{tabular}{lcccc}
\hline Indicators & Factor weight $(\mathrm{b})$ & $\mathrm{SE}$ & $\mathrm{T}$ & $\mathrm{R}^{2}$ \\
\hline K1 Transformational Leadership & 0.94 & 0.04 & $23.10^{* *}$ & 0.91 \\
AA1 Idealized influence* & 0.59 & - & - & 0.77 \\
AA2 Inspirational motivation & 0.49 & 0.01 & $26.27^{* *}$ & 0.70 \\
AA3 Intellectual stimulation & 0.56 & 0.02 & $25.46^{* *}$ & 0.69 \\
AA4 Individualized consideration & 0.64 & 0.02 & $25.39^{* *}$ & 0.77 \\
K2 Strategic Management Leadership & 0.75 & 0.04 & $16.49^{* *}$ & 0.65 \\
BB1 Organizational direction establishment* & 0.52 & - & - & 0.75 \\
BB2 Strategy implementation & 0.57 & 0.02 & $22.93^{* *}$ & 0.80 \\
BB3 Corporate culture & 0.48 & 0.02 & $17.48^{* *}$ & 0.64 \\
BB4 Strategic evaluation and control & 0.55 & 0.03 & $17.57^{* *}$ & 0.62 \\
K3 Academic Leadership & 0.92 & 0.04 & $19.89^{* *}$ & 0.83 \\
CC1 Mission establishment* & 0.50 & - & - & 0.62 \\
CC2 Curriculum and instruction administration & 0.50 & 0.02 & $22.51^{* *}$ & 0.74 \\
CC3 Instructional supervision & 0.48 & 0.02 & $20.12^{* *}$ & 0.69 \\
CC4 Teaching and learning atmosphere enhancement & 0.48 & 0.02 & $17.30^{* *}$ & 0.56 \\
K4 Corporate communication & 0.99 & 0.04 & $21.54^{* *}$ & 0.95 \\
DD1 Reliability of the sender and the source of information* & 0.49 & - & - & 0.61 \\
DD2 Suitability of the situation & 0.44 & 0.02 & $19.69^{* *}$ & 0.61 \\
DD3 Continuation & 0.47 & 0.02 & $22.56^{* *}$ & 0.72 \\
DD4 Communication channels & 0.52 & 0.02 & $22.87^{* *}$ & 0.76 \\
DD6 Clarity of information. & 0.56 & 0.02 & $21.16^{* *}$ & 0.70 \\
K5 Technological skills & 0.92 & 0.04 & $22.29^{* *}$ & 0.83 \\
FF1 Technological vision* & 0.53 & - & - & 0.75 \\
FF2 Technological competency & 0.57 & 0.01 & $29.88^{* *}$ & 0.74 \\
FF3 Support of the use of technology in administration & 0.55 & 0.02 & $24.37^{* *}$ & 0.71 \\
FF4 Support of the use of technology in teaching and learning & 0.62 & 0.02 & $26.19^{* *}$ & 0.79 \\
FF5 Use of technology in measurement and evaluation & 0.48 & 0.02 & $19.03^{* *}$ & 0.56 \\
FF6 Ethics of technology use & 0.42 & 0.02 & $16.53^{* *}$ & 0.42 \\
\hline
\end{tabular}

Note. Chi-square $=357.51, \mathrm{df}=149, \mathrm{p}=0.00000, \mathrm{GFI}=0.94, \mathrm{AGFI}=0.90, \mathrm{RMSEA}=.0 .051, \mathrm{RMR}=0.013, * \mathrm{~A}$ variable that set the parameter to be 1 , so there is no $\mathrm{SE}$, and $\mathrm{T}$ was significant at 0.01 .

Looking closely at the data of the model in Table 2 and Figure 2, Table 1 shows that the overall indicators of all the five elements of the excellent leadership of the private school administrators were positive between 0.75 and 0.99 . They can be ranged in a descending order as K4 Corporate communication 0.99, K1 Transformational Leadership 0.94, K5 Technological skills 0.92, K3 Academic Leadership 0.92, and K2 Strategic Management Leadership 0.75. The variation between the overall indicators and the developed model of the excellent leadership ranged between $65 \%$ and $95 \%$. Each of the indicators showed a statistical significance at 0.01 . This indicated that all these 23 indicators were critical indicators of the 5 elements in the excellent leadership of the private school administrators.

\section{Discussions}

The developed model of the excellent leadership indicators of the private school administrators contained 5 core elements with 82 indicators as follows; 1) transformational leadership with 4 sub-elements and 12 indicators, 2) strategic management leadership with 4 sub-elements and 15 indicators, 3) academic leadership with 4 sub-elements and 14 indicators, 4) corporate communication with 5 sub-elements and 21 indicators, and 5) technological skills with 6 sub-elements and 20 indicators.

Meng (2009) propose six components of a model for excellent leadership of public relations such as teamwork, ethics, relationship building, strategic management, communication management, and dynamic drive to success.

This major finding of the research was in accordance with a study by Purisarn (2017) who conducted a case study on the excellent leadership of "Dr. Magsaysay (A recipient of the Ramon Magsaysay Award" or Professor Dr. Krasae Chanawongse (M.D.). The excellent leadership in that previous research was synthesized and proposed as a model called "Prof. Dr. Krasae Chanawongse's Leadership Model." The proposed model included the following leadership elements; knowledgeability, determination to success, visionary, transformational leader, teamwork, 
communication skills, conflict management, creative, strategic administrator, awareness of technology, and morals and ethics.

The developed model of the excellent leadership indicators of the private school administrators was in consistence with the empirical data (Chi-square $=357.51, \mathrm{df}=149, \mathrm{p}=0.00000, x^{2} / \mathrm{df}=2.39, \mathrm{GFI}=0.94, \mathrm{AGFI}=0.90$, RMSEA $=.0 .051, \mathrm{RMR}=0.013$ ). Considering in more details, it was found that the overall indicators of all the five elements of the excellent leadership of the private school administrators were positive between 0.75 and 0.99 . They can be ranged in a descending order as follows:

Corporate communication with 5 sub-elements and 21 indicators: The 5 sub-elements were rated in a descending order as follows.

1) Clarity of information-The school administrators always chose simple, easy-to-understand, and straightforward language in their communication. They tended to make the communication clear and unambiguous.

2) Communication channels-The school administrators clearly provided written information about the schools' performances for their staff. They had a clear method to process official letters. They gave clearly written assignments to their staff so that they received correct information.

3) Reliability of the sender and the source of information-The teachers provided useful information for the administrators to make use in decision making and school goal setting. In return, the teachers were comprehensively informed of about the school goals.

4) Continuation-The teachers could offer various opinions on the school administration to the administrators. In so doing, the school administrators acted as a sender and receiver of messages. They gave opportunities to other stakeholders to participate in the communication process. Moreover, the school administrators made proactive communication methods to keep their audience informed of up-to-date events.

5) Suitability of the situation-The school administrators selected appropriate language for communication with specific individuals. They also employ various communication tools to support or reinforce their messages so that the communication fit the situation of the receivers. They chose two-way communication and used communication supportive tools to make the audience understand.

This finding of the research was in line with a study by Saengkhammee (2018) who investigated communication characteristics that affected visionary leadership of the school administrators under Phitsanulok Primary Educational Service Area Office 3. The previous study discovered six communication characteristics; 1) reliability of the sender and the source of information, 2) suitability of the situation, 3) continuation, 4) communication channels, 5) capacity of the receiver, and 6) clarity of information.

This finding in the present research accorded with Görkem (2014) who states purposes of communication in an organization as follows; 1) to provide facts and construct good understandings of one another. Verbal or written texts of facts should not be oblique, but concise and clear, (2) to stimulate and convince people to act according to the plan. This requires a great deal of art. Sometimes, idioms are also used to get connected with the nature of the person.

Transformational Leadership with 4 sub-elements and 12 indicators: The 4 sub-elements were rated in a descending order as follows.

1) Individualized consideration-The administrators recognized and appreciated colleagues when they succeeded in performing their tasks. The administrators treated teachers by taking into account their abilities and individual differences.

2) Idealized influence-The administrators showed a strong commitment to accomplishing tasks.

They assured teachers that various problems and obstacles can be overcome.

3) Intellectual stimulation-The administrators highly focused on and listened carefully to suggestions and problems from colleagues. They always encouraged the teachers to be aware of possible problems in advance so that they can come to conclusions for solving them.

4) Inspirational motivation-The administrators continuously promoted teachers to be creative.

They clearly set objectives and goals for tasks. They also strengthened the teachers when they were confronted with barriers.

This finding accorded with research on transformational leadership indicators development for basic education institutions in Chaiyaphum Province, Thailand by Arnupharbsaenyakorn, Thansuwansri, Ariratana, and Teekasap 
(2017). The research found that the transformational leadership comprised 60 indicators in 4 components; 1) Inspirational motivation with 15 indicators weighting between .492-.740, 2) Intellectual stimulation with 17 indicators weighting between .373-.795, 3) Individualized consideration with 16 indicators weighting between .509-.765, and 4) Ideological influence with 12 indicators weighting between .525-.810.

This finding in the present research also supported Bass and Avolio (1994) who summarize that transformational leadership is the process by which leaders influence coworkers and followers. This is done through four specific behavioral components known as "4I's (Four I's)"; 1) ideological influence, 2) inspiration, 3) intellectual stimulation, and 4) individual consideration.

Technological skills with 6 sub-elements and 20 indicators: The 6 sub-elements were rated in a descending order as follows.

1) Technological vision-The administrators had a vision for learning management via appropriate technology. They exhibited proactive thinking behavior such as setting a technological vision for the integration of technology into learning management.

2) Technological competency-The administrators possessed knowledge and understanding of the use of data search engines through the Internet such as Google, Yahoo, etc. They school administrators equipped the teachers and educational personals with knowledge, experience, and skills in the use of technology.

3) Support of the use of technology in administration-The administrators applied technology to the finance and supplies management. They also used technology in the human resource management. These administrators demonstrated behavior in applying technologies in their administration to improve operational efficiency such as measurement and evaluation programs and office package software.

4) Support of the use of technology in teaching and learning-The administrators promoted and support the teachers and educational personals to use information and communication technology (ICT) as part of their learning activity management. The administrators also provided education, trainings, and study visits on ICT management and ICT integration into teaching and learning.

5) Use of technology in measurement and evaluation-The administrators encouraged the analysis and evaluation via technology such as test score-based class placement, final exam results announcement, etc. The administrators specified school's practice guidelines for measurement and evaluation with information technology systems.

6) Ethics of technology use-The administrators employed technology in their work management with morals and ethics. They aimed at developing the school staff to maintain social responsibility, morals, and ethics in the use of ICT.

This finding of the present research was in accordance with a study on school leadership in the digital age by Ratchawong (2019). The elements of the institutional leadership in the digital age included the ability to use technology in teaching and learning, administration, measurement and evaluation, and ethics in the use of technology. Features of the administrators in the digital age were establishing a vision of communication technology and computer technology, infrastructure management to be able to use it more efficiently, promoting the widespread adoption of communication technology and computer technology, training of personnel in communication technology and computer. In addition, school administrators must be able to properly use communication technology and computer technology in their work, promoting, encouraging, motivating teachers and staff to use communication technology and computer technology (ICT) capabilities in learning management and performance. School leaders must supervise, monitor, and advise on the use of communication technology and computer of educational institutions appropriately.

This finding of the present research also supported Weng and Tang (2014) who studied the relationship between technological leadership strategies and school management effectiveness. They found that there were 6 components of technological leadership; 1) technological vision, 2) technological competence, 3) support for the use of technology in management, 4) support for the use of technology in teaching and learning, 5) use of technology in educational measurement and evaluation, and 6) ethical use of technology.

Academic leadership with 4 sub-elements and 14 indicators: The 4 sub-elements were rated in a descending order as follows.

1) Mission establishment-The school administrators set a team of staff to participate in setting academic goals of the schools. The administrators specified clear goals which covered the past and present information on the school performances as well as responsibilities of teachers and students. 
2) Curriculum and instruction administration-The school administrators supported the teachers by providing updated and adequate curriculum materials, budgets, equipment, and teaching audiovisuals. They also encouraged all the teachers to take part in developing the school curriculum.

3) Instructional supervision-The administrators supervised, followed up, helped, and guided the teachers in developing the teaching and learning management. The administrators encouraged the teachers to share experience after the instructional supervision.

4) Student progress monitoring-The school administrators encouraged the teachers to practice a student-centered learning process. They closely monitored and followed up learning activities and student development activities to be in accordance with the curriculum structure. The administrators promoted and supported the development of the school environment that was safe and facilitated learning activities.

The finding in this research was in accordance with a study by Anannawee (2019) on developing indicators for instructional leadership of school administrators in the 21 st century under the offices of basic education commission in the eastern region of Thailand. That previous research discovered 8 elements of instructional leadership: 1) setting goals, vision, and missions of schools (with 4 indicators), 2) promoting academic environment, creating culture, and promoting learning atmosphere (with 3 indicators), 3) curriculum and teaching management (with 2 indicators), 4) supervision and teaching evaluation (with 2 indicators), 5) high expectation communication for students (with 2 indicators), 6) management and team work of administrators (with 3 indicators), 7) creating relationships between the schools and communities (with 2 indicators), and 8) promoting innovation and doing research (with 2 indicators). The indicators validated for instructional leadership of school administrators in 21st Century under the Basic Education Commission in the Eastern were found appropriate, possible and accordance with the results research.

Ruff and Shoho (2005) review case studies of Mental Models that are considered fundamental characteristics of academic leadership. It examined the similarities and differences between the new headteachers and the old ones who had received outstanding awards. It was found that there were different levels of integration. Perceptions about academic leadership were different. This research highlighted the benefits of recognizing patterns in academic leadership discussions. Therefore, it is imperative that school administrators are trained to understand and have academic leadership.

Strategic management leadership with 4 sub-elements and 15 indicators: The 4 sub-elements were rated in a descending order as follows.

1) Strategy implementation-The school administrators specified indicators that would be practiced to suite the school context. They spent budgets under both short-term and long-term action plans.

2) Strategic evaluation and control-The school administrators controlled and evaluated their educational management based on achievement-oriented administration principles. They compared performances with the specified standards and then corrected or improved errors. The school administrators monitored activities and performances.

3) Organizational direction establishment-School staff is aware of their performances according to the visions of the schools. The school administrators also encouraged the staff to work according to the visions of the schools.

4) Corporate culture-The school administrators determined good corporate culture. They encouraged the teachers to follow the good corporate culture. The teachers recognize the importance of the good corporate culture.

This finding was consistent with research by Hitt, Ireland and Hoskisson (2007) who suggest that strategic leadership requires modification and blending between the internal and external environment as well as management and supervision of complex communication processes. The key characteristics of strategic leadership that help operate effectively are identified. They have to consist of the following important characteristics; determining strategic direction, establishing balanced organizational controls, effectively managing the organization's resource portfolio, sustaining an effective organizational culture, and emphasizing ethical practices.

\section{Recommendations}

\subsection{Recommendations for Applying This Research}

1) Office of the Private Education Commission and Office of the Basic Education Commission should add requirements for applying for a school administrator position. A requirement is that a school administration has to pass training on excellent leadership indicators. 
2) According to the research findings, corporate communication had the greatest factor weight. This indicated its importance of excellent leadership. Therefore, school administrators must develop corporate communication. This is because good and effective communication results in better understanding, cooperation, and coordination of all purposes. It leads to correct and suitable operations that meet goals. However, factors to successful communication vary from individuals, supervisors, subordinates, colleagues to communication skills. Successful communication also requires certain morals to perform in an organization. This is to increase the efficiency of the personnel to lead the organization to its goals.

3) Transformational leadership had the second greatest factor weight. This indicated that it is so important that school administrators must develop. The indicators of transformational leadership in this research are as follows; the administrators recognized and appreciated colleagues when they succeeded in performing their tasks, the administrators treated teachers by taking into account their abilities and individual differences, the administrators showed a strong commitment to accomplishing tasks, the administrators assured teachers that various problems and obstacles can be overcome, the administrators highly focused on and listened carefully to suggestions and problems from colleagues, the administrators always encouraged the teachers to be aware of possible problems in advance so that they can come to conclusions for solving them, the administrators continuously promoted teachers to be creative, the administrators clearly set objectives and goals for tasks, and the administrators also strengthened the teachers when they were confronted with barriers.

4) The results of this research highlighted the key components and indicators of excellent leadership of the private school administrators. Therefore, Office of the Private Education Commission and Office of the Basic Education Commission should adapt the five core elements to professional development based on organizational contexts of schools or agents.

\subsection{Recommendations for Further Research}

1) There should be research into constructing a measurement and evaluation tool of excellent leadership of private and basic education school administrators.

2) Research in the form of research and development should be conducted by using the developed model from this research as a guideline to obtain training programs for development of administrators of private schools and other types. They will be expected to have excellent leadership, which will enhance the quality of education.

3) Further research should focus specifically on the development of corporate communication indicators of private and basic education school administrators.

4) Further research should focus specifically on the development of technological leadership indicators of private and basic education school administrators.

5) There should be qualitative research on excellent leadership of administrators of private education institutions and other types. This will be very useful for the selection of school administrators.

\section{Acknowledgments}

This article and the research behind it would not have been possible without the exceptional support of the co-authors. They have given their enthusiasm and guidance throughout the research process. I would like to express my gratitude to the experts for their encouragement and insightful comments. My sincere thanks also go to all the samples at different schools that have fulfilled the research methodology.

I would also like to thank Mr. Yuttachak Lamjuanjit, a lecturer of the Business English Program, Roi Et Rajabhat University, Thailand, for his excellent translation of the original draft into this English article and his assistance and guidance to the entire manuscript preparation and submission process.

\section{References}

Anannawee, P. (2019). The indicators development for instructional leadership of school administrators in 21st century under the Basic Education Commission in the Eastern. Journal of Education, 30(2), 40-53.

Arnupharbsaenyakorn, A., Thansuwansri, K., Ariratana, W., \& Teekasap, S. (2017). Transformational leadership indicators development for basic education institutions in Chaiyaphum Province. Journal of Educational Administration, Khon Kaen University, 13(1), 104-112.

Bass, B. M., \& Avolio, B. J. (1994). Improving organizational effectiveness through transformational leadership. Thousand Oaks, CA: Sage.

Benoit, P. (2003). Leadership excellence: constructing the role of department. Retrieved from https://scholars.fhsu.edu/cgi/viewcontent.cgi?article=1058\& context=alj 
Cavallo, K. (2001). Emotional competence and leadership excellence at Johnson \& Johnson: The emotional intelligence and leadership study. Retrieved from http://www.eiconsortium.org/reports/jj_ei_study.html

Görkem, S. Y. (2014). Corporate communication in large-scale organizations in Turkey: Structure and responsibilities. Public Relations Review, 40(5), 859-861. https://doi.org/10.1016/j.pubrev.2014.07.006

Hitt, M. A., Ireland, R. D., \& Hoskisson, R. E. (2007). Management of strategy: Concepts and cases. China: Thomson South-Western.

Kıral, E. (2020). Excellent leadership theory in education. Journal of Educational Leadership and Policy Studies (JELPS), 4(1), 1-30.

Matichon. (2019). Crisis! In 20194 times of private schools are closed. Retrieved from https://www.matichon.co.th/education/news1590544

McKibben, W. B., Webber, W. B., \& Wahesh, E. (2017). Exploring CSI chapter leaders' development toward leadership Excellence. Retrieved from https://www.researchgate.net/publication/313325147_Exploring_CSI _Chapter_Leaders'_Development_Toward_Leadership_E

Meng, J. (2009). Excellent leadership in public relations: An application of multiple-group confirmatory factor analysis models in assessing cross-national measurement invariance (Unpublished doctoral dissertation). The University of Alabama, Alabama, USA.

Office of the Permanent Secretary, Ministry of Education. (2000). Guidelines for education reform of Ministry of Education. Bangkok: Kurusapa Printing Ladphrao.

Office of the Private Education Commission. (1997). A document set of guidelines for development and quality certification of private education (Vol.1, version of OPEC representatives). Bangkok: Kansatsana Printing House.

Paopan, C. (2016). School administrators in the 21st century. The 1st National Education Conference, Educational Management for Local Development towards ASEAN Community: New Direction in the 21st Century. Kalasin, Thailand: Kalasin University.

Piungam, S., Suwannatrai, W., Pothiwat, S., \& Palajit, S. (2015). The effective leadership of outstanding school administrators: Multi-case studies. Journal of Education Khon Kaen University, 38(4), 168-176.

Purisarn, K. (2017). Excellent leadership: A case study of Dr. Magsaysay, Professor Dr. Krasae Chanawongse (M.D.). College of Asian Scholars Journal, 1(7), 136-141.

Ratchawong, W. (2019). School leadership in the digital age. Journal of Association of Professional Development of Educational Administration of Thailand (JAPDEAT), 1(3), 25-31.

Ruff, W. G., \& Shoho, A. R. (2005). Understanding instructional leadership through the mental models of three elementary school principals. Educational Administration Quarterly, 41(3), 554-577. https://doi.org/10.1177/0013161X04269621

Saengkhammee, S. (2018). Factors of communication characteristics affecting visionary leadership of school administrators under Phitsanulok Primary Educational Service Area Office 3 (Unpublished master's thesis). Pibulsongkram Rajabhat University, Phitsanulok, Thailand.

Sararatana, W. (2004) Leadership: Theories to a proposed model for personnel development programs. Journal of Education Khon Kaen University (EDKKUJ), 27(3), 40-52.

Singmatr, S., Meemana, P., \& Kaewin, D. (2017). Leadership traits of the executive in the 21st century. Paper presented at the Second RMU Graduate Research Conference 2017 at Rajabhat Mahasarakham University.

Srichan, T. (2016). A factor analysis of leadership in the twenty first century of Student Organization Board. Journal of Research Methodology: JRM, 29(2), 1-17.

Sripraseart, S. (2017). Academic leadership of school administrators in opportunity expansion schools under Educational Bureau Pattaya City (Unpublished master's thesis). Burapha University, Chonburi, Thailand.

Teecharoen, C., \& Xupravati, P. (2019). The current and desirable states of technological leadership for secondary school administrators under the Secondary Education Service Area Office 8. An Online Journal of Education, 14(2), 1-12.

Tokeaw, S. (2017). Leadership model of basic education school administrators in the 21st Century (Unpublished doctoral dissertation). Nakhon Sawan Rajabhat University, Nakhon Sawan, Thailand. 
Weng, C. H., \& Tang, Y. (2014). The relationship between technology leadership strategies and effectiveness of school administration: An empirical study. Computers \& Education, 76, 91-107. https://doi.org/10.1016/j.compedu.2014.03.010

Williams, P., \& Denney, J. (2016). Leadership excellence: The seven sides of leadership for the 21st century. Retrieved from https://davekraft.org/wp-content/uploads/Leadership-Excellence.pdf

\section{Copyrights}

Copyright for this article is retained by the author(s), with first publication rights granted to the journal.

This is an open-access article distributed under the terms and conditions of the Creative Commons Attribution license (http://creativecommons.org/licenses/by/4.0/). 